\begin{tabular}{|c|l|}
\hline Title & $\begin{array}{l}\text { Identification and Efficient Utilization of A ntibiotics for the Development of a Stable Transformation System in } \\
\text { Porphyrayezoensis (Bangiales, Rhodophyta) }\end{array}$ \\
\hline Author(s) & Takahashi, Megumu; Mikami, Koji; Mizuta, Hiroyuki; Saga, Naotsune \\
\hline Citation & $\begin{array}{l}\text { Journal of A quaculture Research \& Development, S3, 002 } \\
\text { https://doi.org/10.4172/2155-9546.S3-002 }\end{array}$ \\
\hline Issue Date & 2011 \\
\hline Doc URL & http:/hdl.handle.net/2115/56887 \\
\hline Type & article \\
\hline File Information & Takahashi et al 2011.pdf \\
\hline
\end{tabular}

Instructions for use 


\title{
Identification and Efficient Utilization of Antibiotics for the Development of a Stable Transformation System in Porphyra yezoensis (Bangiales, Rhodophyta)
}

Megumu Takahashi, Koji Mikami, Hiroyuki Mizuta and Naotsune Saga*

Faculty of Fisheries Science, Hokkaido University, Hakodate 041-8611, Japan

\begin{abstract}
Despite the development of transient gene expression in red algae Porphyra species, a stable transformation system has not been established in these algae yet. One reason for the difficulty in the transformation is the lack of a way to select transformed cells from the algae. Thus, to identify antibiotics suitable for the selection of stably transformed cells, we tested the gametophyte for sensitivity to 6 antibiotics, ampicillin (Am), kanamycin (Km), hygromycin $(\mathrm{Hm})$, geneticin $(\mathrm{G} 418)$, chloramphenicol $(\mathrm{Cm})$ and paromomycin $(\mathrm{Pm})$, which are frequently employed as selection agents in the transformation of land plants and microalgae. Sensitivity tests, which were carried out with different concentrations (0-10 mg mL-1) of antibiotics, showed that $\mathrm{Hm}, \mathrm{G} 418, \mathrm{Cm}$ and Pm exhibited a lethal effect at more than $1.0 \mathrm{mg} \mathrm{mL}^{-1}$, suggesting the suitability of these four antibiotics for the selection of genetically transformed cells from $P$. yezoensis gametophytes, while $P$. yezoensis gametophytes were highly resistant to $\mathrm{Am}$ and $\mathrm{Km}$. We also succeeded in reducing the antibiotic concentrations by lowering the $\mathrm{pH}$ value and salt concentration using an artificial synthetic medium. Increasing the sensitivity of gametophytic cells to $\mathrm{Hm}, \mathrm{G} 418, \mathrm{Cm}$ and Pm in the modified synthetic medium will contribute to establishing a genetic transformation system in $P$. yezoensis.
\end{abstract}

Keywords: Antibiotics; Synthetic medium; Gametophyte; Porphyra yezoensis

\section{Introduction}

Microalgae and macroalgae are of great value both as organisms for basic biological research and as resources for bio-industry. That is why algae are now considered to be very promising organisms for economical and industrial applications and are the target of genetic transformation $[1,2]$. Recently, such transformation has been performed successfully in microalgae, and stably transformed microalgae have been employed to produce useful materials and to analyze the gene functions required for engineering these materials [3-5]. However, it is still hard to establish transgenic macroalgae, which is hindering our understanding of gene functions in various physiological regulations and also slowing our utilization of macroalgae in biotechnological applications.

The red macroalga Porphyra yezoensis is the most popular sea crop in Asia [6] and has recently received a great deal of attention as a model macrophyte for physiological and molecular biological studies in marine red algae $[7,8]$. To date, several studies have described the establishment of a transient gene expression system in P. yezoensis [9]; for example, we have succeeded in eliciting the efficient expression of the codon-modified $\beta$-glucuronidase (PyGUS) and humanized cyan and green fluorescent protein (AmCFP and ZsGFP) genes by transient transformation of $P$. yezoensis gametophytes using particle bombardment [10-13], which was then adapted to other Bangiophycean algae $[14,15]$. Despite the development of transient gene expression systems in $P$. yezoensis, a stable transformation system, which is needed for the fine analysis of gene function, has not been established, because of a lack of techniques to select and isolate stably transformed cells from gametophytes.

The availability of a useful selection protocol, which depends on the choice of a selection agent such as antibiotics and herbicides, is generally a prerequisite for the development of a stable transformation system [16]. Thus, the identification of selection agents such as antibiotics and herbicides was carried out in P. yezoensis [17], and it resulted in the indication of the non-sensitivity of $P$. yezoensis gametophytes to many kinds of antibiotics at concentrations up to $5 \mathrm{mg}$ ml- ${ }^{-1}$ in culture medium; however, the reproducibility of the test results was not examined. Therefore, we here identified a selection agent for a stable transformation system in $P$. yezoensis gametophytes by reexamining the sensitivity to 4 antibiotics used in the previous study, ampicillin, kanamycin, hygromycin B and geneticin [17], as well as that of chloramphenicol and paromomycin. In addition, since the high salt conditions often reduced the action of antibiotics in many marine algae [18] and high $\mathrm{pH}$ levels of the medium affected the toxicity of the antibiotic trimethoprim (TMP) for the willow tree Salix viminalis [19], we also investigated using an artificial synthetic medium to determine whether modification of the medium conditions in terms of $\mathrm{pH}$ value and salt concentration would affect the antibiotic sensitivity of $P$. yezoensis gametophytes.

\section{Materials and Methods}

Gametophytes of $P$. yezoensis (strain TU-1;[20]), 2-3 mm long, were cultured for 4 weeks in $1 \mathrm{~L}$ of enriched sea life (ESL) medium [21] at $15^{\circ} \mathrm{C}$ with a cycle of $60 \mu \mathrm{mol} \mathrm{m}-^{2} \mathrm{~s}^{-1}$ under irradiance for 10 $\mathrm{h}$ and darkness for $14 \mathrm{~h}$. The ESL medium was continuously bubbled with filter-sterilized air and renewed weekly. Gametophytes of ca. 1.5

*Corresponding author: Naotsune Saga, Faculty of Fisheries Science, Hokkaido University, Hakodate 041-8611, Japan, Tel/Fax: +81 13840 5533, E-mail: nsaga@ fish.hokudai.ac.jp

Received November 01, 2011; Accepted December 14, 2011; Published December 23, 2011

Citation: Takahashi M, Mikami K, Mizuta H, Saga N (2011) Identification and Efficient Utilization of Antibiotics for the Development of a Stable Transformation System in Porphyra yezoensis (Bangiales, Rhodophyta). J Aquac Res Development 2:118 doi:10.4172/2155-9546.1000118

Copyright: @ 2011 Takahashi M, et al. This is an open-access article distributed under the terms of the Creative Commons Attribution License, which permits unrestricted use, distribution, and reproduction in any medium, provided the original author and source are credited. 
$\mathrm{cm}$ length were used for sensitivity testing of antibiotics. Solutions of ampicillin (Am; Wako Pure Chemical Industries, Japan), kanamycin (Km; Wako Pure Chemical Industries, Japan), hygromycin (Hm; Wako Pure Chemical Industries, Japan), geneticin (Gm; Wako Pure Chemical Industries, Japan) and paromomycin (Pm; Sigma, USA) were prepared in ESL medium. Chloramphenicol (Cm; Wako Pure Chemical Industries, Japan) was prepared in ESL medium by dilution of stock solutions (500 $\mathrm{mg} \mathrm{mL}^{-1}$ ) resolved in dimethyl sulfoxide (DMSO; Wako Pure Chemical Industries, Japan) the concentration of which did not exceed $2 \%$ in the dilution. Media containing an antibiotic were finally adjusted to $\mathrm{pH} 8.0$ with $\mathrm{NaOH}$ or $\mathrm{HCl}$.

Sensitivity of $P$. yezoensis gametophytes to 6 antibiotics was first tested in standing culture as follows. Gametophytes were transferred into a well of 6-well plate (5 individuals/well)(Iwaki Sci Tech Div., Asahi Techno Glass, Japan) containing $5 \mathrm{~mL}$ ESL medium with one antibiotic (Am, Km, Hm, G418, Cm or Pm) and incubated for 2 weeks at $15^{\circ} \mathrm{C}$, with the medium containing antibiotic renewed weekly. After cultivation, cell mortality of gametophyte was estimated by staining with $0.01 \%$ erythrosine (Wako Pure Chemical Industries, Japan)containing ESL medium according to the previous report [22] with slight modifications. After staining for $5 \mathrm{~min}$ at room temperature, gametophytes were gently rinsed with ESL medium to remove excess erythrosine and mounted on a slide with ESL medium. Gametophytes were observed and photographed using a Leica DM 5000 B light microscope equipped with a Leica DFC 300 FX camera. In this study, we defined the sensitivity to antibiotics based on the death of gametophyte cells which were stained by the dye. The cell mortality was measured by counting the living and dead gametophyte cells using photographs.

To examine the effects of bubbling culture on the sensitivity of gametophytes to antibiotics, we transferred 5 gametophytes into a 100$\mathrm{mL}$ glass flask (Iwaki Sci Tech Div., Asahi Techno Glass, Japan) in 50 $\mathrm{mL}$ of ESL medium containing various concentrations of antibiotics (Hm, G418, Cm and Pm) and incubated the samples for 2 weeks at $15^{\circ} \mathrm{C}$ under $60 \mu \mathrm{mol} \mathrm{m}-^{2} \mathrm{~s}^{1}$. The culture medium was continuously bubbled with filter-sterilized air and renewed weekly. The sensitivity test was carried out as described above.

To identify factors influencing the susceptibility of $P$. yezoensis gametophytes to antibiotics, we examined the antibiotic sensitivity test using artificial synthetic medium ASPMT3 [23]. Low-salt medium was made by reducing $\mathrm{NaCl}$ from $28 \mathrm{~g} \mathrm{~L}^{-1}$ to $14 \mathrm{~g} \mathrm{~L}^{-1}$ in ASPMT3, and two $\mathrm{pH}$-modified media were prepared by changing the buffering agent from HEPES (4-(2-hydroxyethyl)-1-piperazineethanesulfonic acid; Sigma, USA, pH 8.0) to MES (2-(N-morpholino) ethanesulfonic acid; Dojin Laboratories, Japan, $\mathrm{pH}$ 6.0) or CHES (N-Cyclohexyl2-aminoethanesulfonic acid; Dojin Laboratories, Japan, $\mathrm{pH}$ 10) in ASPMT3. Cultivation and sensitivity tests of $P$. yezoensis gametophytes to antibiotics were carried out as described above.

\section{Results and Discussion}

We first tested the sensitivity of $P$. yezoensis gametophytes to 6 antibiotics in standing culture. The gametophytes were insensitive to $\mathrm{Am}$ and $\mathrm{Km}$ at less than $10 \mathrm{mg} \mathrm{mL}^{-1}$ (Figure $1 \mathrm{~A}$ ), although the somatic cells showed dark color or discoloration and also round shape (Supplementary Figure $1 \mathrm{~A}-\mathrm{C}$ ). In contrast, $P$. yezoensis gametophytes were highly sensitivity to $\mathrm{Hm}, \mathrm{G} 418, \mathrm{Cm}$ and Pm (Figure $1 \mathrm{~A}$ and Supplementary Figure 1D-G). Next, we examined the effects of bubbling culture on the sensitivity of gametophytes to $\mathrm{Hm}, \mathrm{G} 418, \mathrm{Cm}$ and $\mathrm{Pm}$. Survival rates of gametophytes decreased to $0 \%$ by using more than $2.0 \mathrm{mg} \mathrm{mL}^{-1}$ of $\mathrm{Hm}, \mathrm{Cm}$ and $\mathrm{Pm}$ and $1.0 \mathrm{mg} \mathrm{mL}^{-1}$ of G418 (Figure 2),
A

\begin{tabular}{lccc}
\hline & \multicolumn{3}{c}{ Concentrations $\left(\mathrm{mg} \mathrm{mL}^{-1}\right)$} \\
\cline { 2 - 4 } Agents (Abbrev.) & 2.0 & 6.0 & 10.0 \\
\hline Ampicillin (Am) & - & - & - \\
Kanamycin (Km) & - & - & - \\
Hygromycin (Hm) & + & + & + \\
Geneticin (G418) & + & + & + \\
Chloramphenicol $(\mathrm{Cm})$ & + & + & + \\
Paromomycin (Pm) & + & + & + \\
\hline
\end{tabular}

B

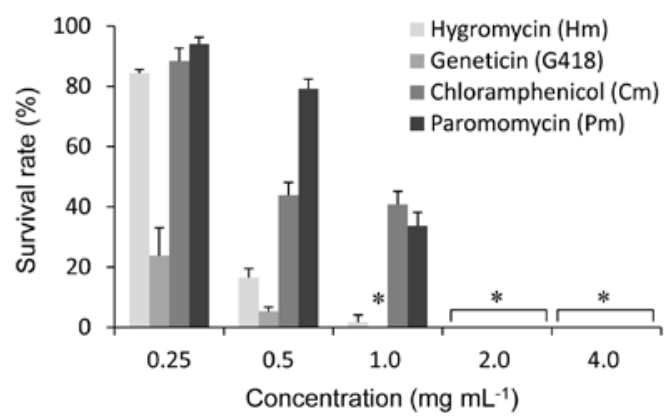

* shows that the survival rate was $0 \%$.

Figure 1: Effects of antibiotics on survival of $P$. yezoensis gametophytic cells (A) Sensitivity to antibiotics of $P$. yezoensis gametophytic cells cultured in ESL medium with antibiotics after 2 weeks. The sensitivity of the gametophytes to each antibiotic is shown as + (observed) or - (not observed). (B) The survival rate of $P$. yezoensis gametophytic cells in various concentrations of antibiotics. The survival rate was measured by counting the living and dead cells of gametophytes cultured in ESL medium containing antibiotics at $15^{\circ} \mathrm{C}$ with a cycle of $60 \mu \mathrm{mol} \mathrm{m}-^{2} \mathrm{~s}^{-1}$ irradiance for $10 \mathrm{~h}$ and darkness for $14 \mathrm{~h}$ for 2 weeks. Values are the mean \pm SD $(n=30)$.

although both living and divided cells were observed in gametophytes cultured with less than $1.0 \mathrm{mg} \mathrm{mL}^{-1}$ of these antibiotics, except for G418 (Figure 2). Therefore, $1.0 \mathrm{mg} \mathrm{mL}^{-1}$ of G418 and $2.0 \mathrm{mg} \mathrm{mL}^{-1}$ of $\mathrm{Hm}$, $\mathrm{Cm}$ and $\mathrm{Pm}$ are considered to be effective agents for the selection of transformed cells from gametophytes.

We also examined whether the salt concentration and $\mathrm{pH}$ value affected the sensitivity of gametophytic cells to develop an effective selection system by using artificial synthetic medium. The survival rate of gametophyte cells was significantly lower with $1.0 \mathrm{mg} \mathrm{mL}^{-1}$ of $\mathrm{Hm}$ in low-salt ASPMT3 than that in standard ASPMT3 (Figure 2a) (Student's t-test $\mathrm{p}<0.05$ ). In the case of changing $\mathrm{pH}$ values, survival rates of gametophyte cells were high in ASPMT3 at pH 10, except in the case of $4.0 \mathrm{mg} \mathrm{mL}^{-1}$ of $\mathrm{Hm}$ (Figure $2 \mathrm{~b}$ ). In contrast, gametophytic cells cultured in ASPMT3 containing $1.0 \mathrm{mg} \mathrm{mL}^{-1}$ of $\mathrm{Hm}$ at $\mathrm{pH} 6.0$ showed a significantly lower survival rate compared with that in ASPMT3 at $\mathrm{pH} 10$ and $\mathrm{pH} 8.0$ (Figure 2b) (Student's t-test $\mathrm{p}<0.05$ ). Moreover, the combination of low $\mathrm{pH}(6.0)$ and low salt decreased the survival rates of gametophytic cells to less that $20 \%$ in all concentrations of Hm (Figure $2 \mathrm{c})$. The same results were also obtained by using other antibiotics (G418, Cm and Pm) in modified ASPMT3 (Table 1). Thus, we clarified that the antibiotic concentration for the selection of transformed cells can be reduced by using a low salt concentration and a low $\mathrm{pH}$ value in the culture medium.

In the present study, we have succeeded in finding antibiotics, 
A

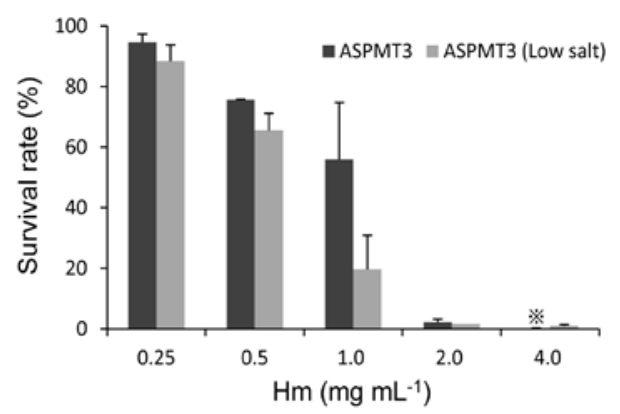

B

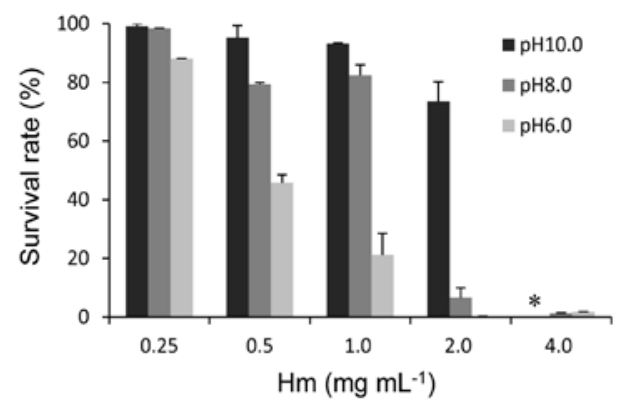

$\mathrm{C}$

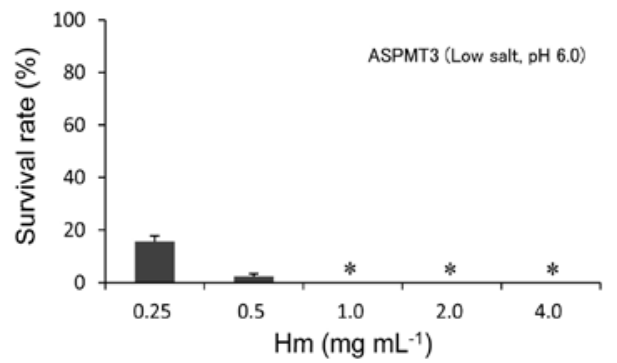

Figure 2: The survival rate of $P$. yezoensis gametophytic cells in various hygromycin B concentrations in modified ASPMT3. (A) Salt concentrations, (B) $\mathrm{pH}$ values and $(\mathrm{C})$ combination of salt concentration and $\mathrm{pH}$ value. The survival rate was measured by counting the living and dead cells of gametophytes cultured in culture medium containing hygromycin $\mathrm{B}$ at $15^{\circ} \mathrm{C}$ with a cycle of 60 $\mu \mathrm{mol} \mathrm{m} \mathrm{m}^{-2} \mathrm{~s}^{-1}$ irradiance for $10 \mathrm{~h}$ and darkness for $14 \mathrm{~h}$ for 2 weeks. Values are the mean $\pm \operatorname{SD}(n=30)$. * shows that the survival rate was $0 \%$.

\begin{tabular}{|l|l|l|l|l|l|l|l|l|l|l|l|}
\hline & \multicolumn{9}{l|}{\begin{tabular}{l} 
Concentrations (mg mL-1) \\
\cline { 2 - 3 }
\end{tabular}} & \multicolumn{10}{l|}{$\begin{array}{l}\text { Modified ASPMT3 } \\
\text { (Low salt, pH 6.0) }\end{array}$} \\
\hline Agents & 0.25 & 0.5 & 1.0 & 2.0 & 4.0 & 0.25 & 0.5 & 1.0 & 2.0 & 4.0 \\
\hline Geneticin (G418) & 23.8 & 5.3 & 0 & 0 & 0 & 0 & 0 & 0 & 0 & 0 \\
\hline $\begin{array}{l}\text { Chloramphenicol } \\
\text { (Cm) }\end{array}$ & 88.4 & 43.8 & 40.8 & 0 & 0 & 6.2 & 1.3 & 0 & 0 & 0 \\
\hline Paromomycin (Pm) & 93.9 & 79.1 & 33.7 & 0 & 0 & 12.8 & 0 & 0 & 0 & 0 \\
\hline
\end{tabular}

The number indicates survival rate of gametophyte cells (\%).

Table 1: Comparison of the antibiotic effect to $P$. yezoensis gametophytes in different culture media between ESL and modified ASPMT3

$\mathrm{Hm}, \mathrm{G} 418, \mathrm{Cm}$ and $\mathrm{Pm}$, as candidates of selection agents useful for the stable transformation of $P$. yezoensis gametophytes (Figure 1B and Supplementary Figure 1). Furthermore, the aeration cultivation was considered to be effective for a selection system of transformed cells from gametophytes, since living gametophytic cells are often observed in standing culture compared with aeration culture at the same antibiotic concentration (data not shown). In bubbling culture, $P$. yezoensis gametophytic cells were sensitive to more than 1.0$2.0 \mathrm{mg} \mathrm{mL}-1$ of antibiotic concentration (Figure 1B); however, this concentration is very high in comparison with the cases for other algae. For example, the red alga Griffithsia japonica and the green alga Chlamydomonas reinhardtii were highly sensitive to $50 \mathrm{mg} \mathrm{mL}^{-1}$ and $1.0 \mathrm{mg} \mathrm{mL}^{-1}$ of Hm [24,25], while P. yezoensis gametophytes cultured in ESL medium were sensitive to $2.0 \mathrm{mg} \mathrm{mL}^{-1}$ of $\mathrm{Hm}$ (Figure 1B). It is possible that the differences in cell structure and cell wall composition between unicellular and multicellular algae might affect the sensitivity to antibiotics.

Changing the composition of the culture medium may be effective for reducing the antibiotic concentration for various algae [18]. Therefore, we tested whether salt and $\mathrm{pH}$ levels affect the sensitivity to antibiotics for the improvement of selection efficiency in transformed gametophytic cells and found that the antibiotics concentration for the selection of transformed cells can be reduced by using a low salt concentration and low $\mathrm{pH}$ value in the culture medium (Figure 2 and Table 1). In the unicellular microalga Dunaliella bardawil, a low salt concentration in the growth media can significantly affect the efficacy of $\mathrm{Hm}$ [26]. On the other hand, high-salt growth media of Dunaliella can significantly reduce the efficacy of various antibiotics and herbicides [18]. In addition, changing the salinity and $\mathrm{pH}$ values of culture medium also affects the growth rate and photosynthesis activity in $P$. tenera and $P$. umbilicalis $[27,28]$. Similar physiological changes are considered to occur in $P$. yezoensis, which results in enhancing the effective influence of antibiotics to gametophytic cells. Moreover, the lethal concentration was significantly lower in modified ASPMT3 than in ESL (Table 1). Using the antibiotic medium with low $\mathrm{pH}$ and low salt concentration is more economical, which is important, since large amounts of expensive antibiotics are used in this process.

The antibiotics such as Hm, G418, Cm and Pm are frequently used selection agents for obtaining transgenic prokaryotic and eukaryotic cells, for which selectable marker genes have been established. For example, in the green alga Chlamydomonas reinhardtii, the aminoglycoside phosphotransferase aph 7 " gene from Streptomyces hygroscopicus and the aminoglycoside phosphotransferase aphVIII $(a p h H)$ gene from Streptomyces rimosus had been reported as selectable marker genes for hygromycin B and paromomycin, respectively $[25,29]$. Similarly, in the multicellular green alga Volvox carteri, the aminoglycoside phosphotransferase aphVIII $(a p h H)$ gene from $S$. rimosus had been used as a paromomycin-resistance gene [30,31]. In the diatom Phaeodactylum tricornutum, the expressed chloramphenicol acetyltransferase gene (CAT) detoxifies chloramphenicol [32], and the neomycin phosphotransferase II (nptII) gene confers resistance to the aminoglycoside antibiotic G418 [33]. Likewise, the nptII gene gives resistance to the antibiotic G418 in the diatoms Navicula saprophila and Cyclotella cryptica [34]. However, it is unknown whether these selection marker genes are available for $P$. yezoensis. Thus, it is necessary to confirm whether $P$. yezoensis gametophytes will obtain the antibiotic tolerance by introducing plasmid constructs containing the antibiotic-resistance genes mentioned above. Such efforts are expected to contribute to the establishment of a stable transformation system in P. yezoensis.

\section{Acknowledgement}

We are grateful to Dr. Hajime Yasui (Hokkaido University, Japan) for kindly providing microscopes and to our colleagues for helpful discussions. This study was supported in part by the Regional Innovation Cluster Program (Global Type) from the Ministry of Education, Culture, Sports, Science and Technology, Japan to N. S. 
Citation: Takahashi M, Mikami K, Mizuta H, Saga N (2011) Identification and Efficient Utilization of Antibiotics for the Development of a Stable Transformation System in Porphyra yezoensis (Bangiales, Rhodophyta). J Aquac Res Development 2:118 doi:10.4172/2155-9546.1000118

\section{References}

1. Walker TL, Becker DK, Collet C (2005) Characterisation of the Dunaliella tertiolecta RbcS genes and their promoter activity in Chlamydomonas reinhardtii. Plant Cell Rep 23: 727-735.

2. Hallmann A (2007) Algal transgenics and biotechnology. In: Teixeira da Silva JA, Shima K (eds), Transgenic Plant Journal, Global Science Books, UK, pp. $81-98$

3. Sun M, Qian K, Su N, Chang H, Liu J, et al. (2003) Foot-and-mouth disease virus VP1 protein fused with cholera toxin B subunit expressed in Chlamydomonas reinhardtii chloroplast. Biotechnol Lett 25: 1087-1092.

4. Specht E, Miyake-Stoner S, Mayfesqaxeld S (2010) Micro-algae come of age as a platform for recombinant protein production. Biotechnol Lett 32: 13731383.

5. Wu S, Huang R, Xu L, Yan G, Wang Q (2010) Improved hydrogen production with expression of hemH and lba genes in chloroplast of Chlamydomonas reinhardtii. J Biotechnol 146: 120-125.

6. Oohusa T (1993) Recent trends in nori products and markets in Asia. J App Phycol 5: 155-159.

7. Saga N, Kitade Y (2002) Porphyra: a model plant in marine sciences. Fish Sci 68: 1075-1078.

8. Waaland JR, Stiller JW, Cheney DP (2004) Macroalgal candidates for genomics. J Phycol 40: 26-33.

9. Mikami K, Hirata R, Takahashi M, Uji T, Saga N (2011) Transient transformation of red algal cells: breakthrough toward genetic transformation of marine crop Porphyra species. In: Alvarez M (ed), Genetic Transformation. InTech - Open Access Publisher, Croatia, pp. 241-258.

10. Fukuda S, Mikami K, Uji T, Park E-J, Ohba T, et al. (2008) Factor influencing efficiency of transient gene expression in the red macrophyte Porphrya yezoensis. Plant Sci 174: 329-339.

11. Mikami K, Uji T, Li L, Takahashi M, Yasui H, et al. (2009) Visualization of phosphoinositides via the development of the transient expression system of a cyan fluorescent protein in the red alga Porphyra yezoensis. Mar Biotechno 11: 563-569.

12. Uji T, Takahashi M, Saga N, Mikami K (2010) Visualization of nuclear localization of transcription factors with cyan and green fluorescent proteins in the red alga Porphyra yezoensis. Mar Biotechnol 12: 150-159.

13. Takahashi M, Uji T, Saga N, Mikami K (2010) Isolation and regeneration of transiently transformed protoplasts from gametophytic blades of the marine red alga Porphyra yezoensis. Electron J Biotechnol 13 doi: 10.2225/vol13-issue2fulltext-7.

14. Hirata R, Takahashi M, Saga N, Mikami K (2011) Transient gene expression system established in Porphyra yezoensis is widely applicable in Bangiophycean algae. Mar Biotechnol 13: 1038-1047.

15. Hirata R, Jeong WJ, Saga N, Mikami K (2011) Heterologous activation of the Porphyra tenera HSP70 promoter in Bangiophycean algal cells. Bioeng Bugs 2: 271-274.

16. Nehra NS, Chibbar RN, Leung N, Caswell K, Mallard C, et al. (1994) Self-fertile transgenic wheat plants regenerated from isolated scutellar tissues following microprojectile bombardment with two distinct gene constructs. Plant J 5: 285297.

17. Fukuda S, Nagata N, Ootsuka S, Endo H, Kitade Y, et al. (2005) Research on the drug susceptibility in the gametophytes of Porphyra yezoensis (Bangiales, Rhodophyta). Fish Gene Breed Sci 34: 129-141. (in Japanese with English abstract).

18. Allnutt FCT, Kyle DJ, Grossman AR, Apt KE (2000) Methods and tools for transformation of eukaryotic algae. United States of America Patent no. 6027900.

19. Mikes O, Trapp S (2010) Acute toxicity of the dissociating veterinary antibiotics trimethoprim to willow tree at varying $\mathrm{pH}$. Bull Environ Contam Toxicol 85: 556561.

20. Kuwano K, Aruga Y, Saga N (1996) Cryopreservation of clonal gametophytic thalli of Porphyra (Rhodophyta). Plant Sci 116: 117-124.

21. Kitade $Y$, Fukuda S, Nakajima M, Watanabe $T$, Saga N (2002) Isolation of a cDNA encoding a homolog of actin from Porphyra yezoensis (Rhodophyta). J Appl Phycol 14: 135-141.
22. Saga N, Sakanishi Y, Ogishima T (1989) Method for quick evaluation of cell viability in marine macroalgae. Jpn J Phycol 37: 129-136.

23. Takahashi M, Saga N, Mikami K (2010) Photosynthesis-dependent extracellula $\mathrm{Ca}^{+}$influx triggers an asexual reproductive cycle in the marine red macroalga Porphyra yezoensis. Am J Plant Sci 1: 1-11.

24. Lee YK, An G, Lee IK (2000) Antibiotics resistance of a red alga, Griffithsia japonica. J Plant Biol 43: 179-182.

25. Berthold P, Schmitt R, Mages W (2002) An engineered Streptomyce hygroscopicus aph 7" gene mediates dominant resistance against hygromycin B in Chlamydomonas reinhardtii. Protist 153: 401-412.

26. Anila N, Chandrashekar A, Ravishankar GA, Sarada R (2011) Establishment of Agrobacterium tumefaciens-mediated genetic transformation in Dunaliella bardawil. Eur J Phycol 46: 36-44.

27. Ogata E, Matsui T (1965) Photosynthesis in several marine plants of Japan as affected by salinity, drying and $\mathrm{pH}$, with attention to their growth habitats. Bot Mar 8: 199-217.

28. Ogata E, Schramm W (1971) Some observation on the influence of salinity on growth and photosynthesis in Porphyra umbilicalis. Mar Biol 10: 70-76.

29. Sizova I, Fuhrmann M, Hegemann P (2001) A Streptomyces rimosus aphVIII gene coding for a new type phosphotransferase provides stable antibiotic resistance Chlamydomonas reinhardtii. Gene 277: 221-229.

30. Jakobiak T, Mages W, Scharf B, Babinger P, Stark K, et al. (2004) The bacteria paromomycin resistance gene, $a p h H$, as a dominant selectable marker in Volvox carteri. Protist 155: 381-393

31. Hallmann A, Wodniok S (2006) Swapped green algal promoters: aphVIII based gene constructs with Chlamydomonas flanking sequences work as dominan selectable markers in Volvox and vice versa. Plant Cell Rep 25: 582-591.

32. Apt KE, Kroth-Pancic PG, Grossman AR (1996) Stable nuclear transformation of the diatom Phaeodactylum tricornutum. Mol Gen Genet 252: 572-579.

33. Zaslavskaia LA, Lippmeier JC, Kroth PG, Grossman AR, Apt KE (2000) Transformation of the diatom Phaeodactylum tricornutum (Bacillariophyceae) with a variety of selectable marker and reporter gene. J Phycol 36: 379-386.

34. Dunahay TG, Jarvis EE, Roessler PG (1995) Genetic transformation of the diatom Cyclotella cryptic and Navicula saprophila. J Phycol 31: 1004-1012.

\section{Submit your next manuscript and get advantages of OMICS} Group submissions

Unique features:

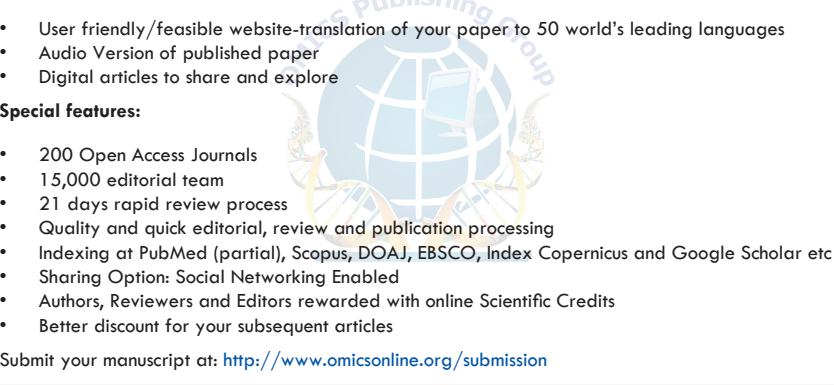



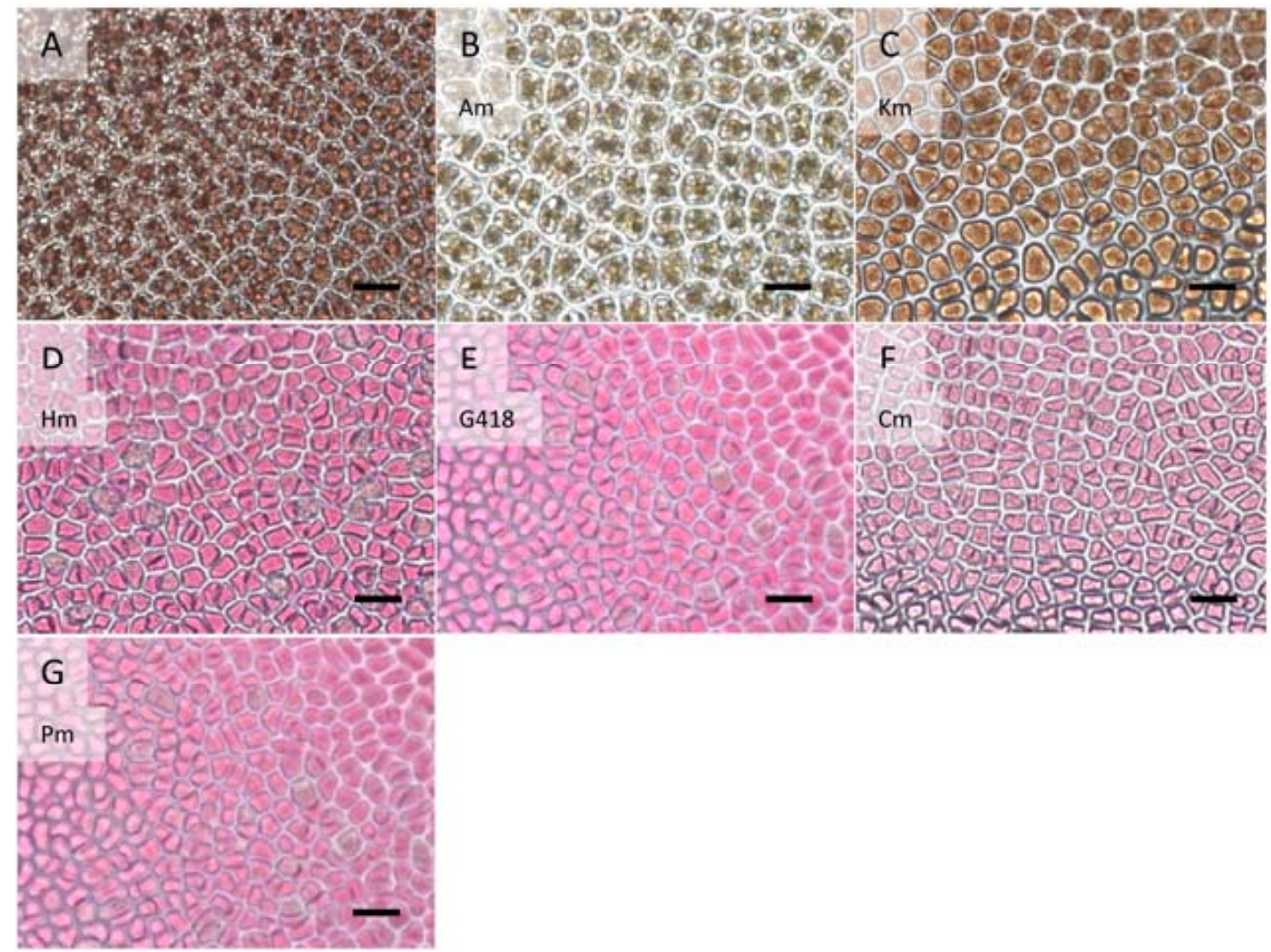

Supplementary Figure 1. Effects of antibiotics on survival of $P$. yezoensis gametophytic cells. Gametophytes were cultured in ESL medium with $10 \mathrm{mg}$ $\mathrm{mL}^{-1}$ concentration of antibiotics at $15^{\circ} \mathrm{C}$ with a cycle of $60 \mu \mathrm{mol} \mathrm{m} \mathrm{m}^{-2} \mathrm{~s}^{-1}$ irradiance for $10 \mathrm{~h}$ and darkness for $14 \mathrm{~h}$ for 2 weeks and then stained with $0.01 \%$ erythrosine solution. (A) control, (B) ampicillin, (C) kanamycin, (D) hygromycin $B,(E)$ geneticin, $(F)$ chloramphenicol and $(G)$ paromomycin. The cells stained pink are dead. Scale bars: $20 \mu \mathrm{m}$. 